\title{
The Legal Aspects of Social Safety of Senior Citizens in Bangladesh
}

\author{
Md. Abdullah Al Mamun (Associate Professor)
}

Faculty of Law, University of Chittagong, Bangladesh

\author{
Tanzina Alam Chowdhury (Assistant Professor) \\ Department of Law, Premier University, Chittagong, Bangladesh
}

\section{Doi: 10.19044/elp.v8no1a1 URL:http://dx.doi.org/10.19044/elp.v8no1a1}

\begin{abstract}
This paper explores the vulnerability and sufferings of the old-age people of Bangladesh in respect to health care, economic, and social protections. The article presents an analytical and conceptual approach to the socio-economic status of old-aged people in Bangladesh while focusing on the global context. The numbers of old-aged persons are increasing in the last years due to decreasing mortality rate and increasing life expectancy of the people as a result of improvement of the health sector in Bangladesh. Older persons need food with nutrient, proper and regular healthcare, adequate and comfortable living place, access to law, if necessary, proper recreation and more significantly the company of others which is very crucial in old age. Development of the so-called nucleus family in today's modern society, which means a family staying away from their parents, put the aged persons in very miserable conditions in our society. The right to enjoyment of the basic rights by the elderly people is recognized by the Constitution of the People's Republic of Bangladesh. This paper focuses on analyzing the National Policy and legal framework for upholding and protecting the rights, socio-economic development, and welfare concerns of elderly people in Bangladesh. There is an endeavor to explore the challenges which are standing as obstacles in ensuring the protection of the rights of old-age people and the development of their socio-economic condition in Bangladesh. Research methods used in this paper are documentation, analytical, comparative, and logical method. Authors tried to show that senior citizen of the society should get legal and moral protection from the family, society, and the state.
\end{abstract}

Keywords: Senior citizen, old-age home, maintenance, health care, old-age allowance, legal protection 


\section{Introduction}

Bangladesh is currently experiencing the emerging challenge of population aging bearing more than ten millions ( 1.4 crores) of senior citizens and they are increasing by 4.41 percent every year (National Policy of Older Persons, 2013). The older people are about 8 percent of the country's total population and the number will grow to 5 crores by 2050 (UNDP, 2018). The old people will occupy 19 percent of the total population in developing countries within the next 50 years (National Policy of Older Persons, 2013). This demographic conversion will affect severely the personal, social, national, and socio-economic life of the people. Old age is one of the problems of the world as the older people suffer a lot from age-related problems. Therefore, the older people are growing faster than other age groups. They are more vulnerable, especially the women, as a result of socio-economic conditions. Many countries are facing economic and political pressures regarding the public system of health care, pension, and social protections for the older section of people (UNDP, Bangladesh, 2018). This issue is becoming a big concern in regards to the fiscal demands of the government. Human rights issues of older persons are often neglected in the national plan, policies, actions, and laws (Hossain, 2018).

\section{Who are the Senior Citizens in the Society?}

Old age is the later part of life after youth and middle age. It comes in a natural way. Scientists determine old age on the criterion of age considering the physical, psychological, behavioral, social, and cultural issues of the people (National Policy of Older Persons, 2013). However, we do not find any universal definition of old people though the United Nations considers older persons to be 60 years and above (UN, 2019). In most of the literatures, the sixty plus years is regarded as the mark of elderly people. The Madrid International Plan of Action on Aging considered someone who is at the age of 60 years or more as an old person (Art. 2, 2002). In most developed western countries, the age of 60-65 is considered as eligibility criteria to get the oldage social security benefits (Barry, wikipedia, 2020). In majority of those countries, people generally retire at 60-65 when the persons enter into old age segment. The National Policy of Older Persons (2013) specifies the mark of 60 years or more to recognize a person to be older. In the last few years, old persons are increasing day by day due to decreasing mortality rate and increasing life expectancy of the people for the improvement of the health sector in Bangladesh. The older persons were 6.1 percent of the population in the year 2001, and it will be 20 percent in 2050 (National Policy of Older Persons, 2013).

\section{A Trend of Change in Social Respect to Elder Persons}

There was a culture of respecting elder persons in Bangladesh as well as in other countries of the Indian Sub-continent irrespective of their religions and social status. The seniors were given priority in taking decisions on different social matters as well as in family matters. They were respected by 
any unknown persons even with different social greetings. The older unknown people were often addressed by any young person who is a stranger by the socially respecting words, such as, 'uncle', 'aunt', 'grandfather', 'grandmother', etc. (Siddiqui, 2013). Even slightly older persons were referred to as an 'elder brother' or 'elder sister'. This social and cultural value of honoring the elders was very strong especially in the rural areas of the country. The families were united and there was strong family bonding among the members. They would care, help, and co-operate with each other in every psychological, financial, physical and social needs. Recently, the culture of honor towards the older persons is changing, especially in the urban areas, and families are disintegrating. The new younger generation prefers western culture of nucleus family, i.e., living away from their parents (Siddiqui, 2013). They are now becoming less caring about the elderly persons of the family. Many older persons are even not getting their basic necessities from their family members. Thus, this new style of the society is pushing the senior persons into miserable situations.

\section{Problems Faced by Older People}

Older people oftentimes lose their physical ability. For this reason, they develop physical and mental illness, decreased mobility, loss of sight and hearing, and weaker muscle and strength. They become too much sensitive to cold and hot weather. The old body becomes vulnerable to any rough situation. Osteoporosis, Arthritis, Heart Disease, Obesity, Diabetes, Hypertension, Stroke, etc. are the common diseases for old people. So, older persons are in need of regular health care. Nonetheless, many elder members do not get proper and adequate medical care from the society and they suffer untreated illness. This makes them go through an unbearable physical sufferings and finally to untreated-death. The elder citizens of the developed countries are now facing another problem of increased longevity. A long life of eighty or ninety years without proper care and support from the family members again creates other mental problems, such as, Dementia, Depression, and Loneliness.

Again, due to inabilityto work, millions of seniors experience chronic poverty. Poverty and unemployment make the older persons helpless to the others and this situation creates other problems, such as homelessness or inadequate shelter, lack of nutrient food, isolation, no access to law, etc. However, there is no available scope to use the seniors' experience in the job market. So, most of the older persons remain unemployed. Sometimes, the older persons require the help of the law to establish their proprietary rights. Nevertheless, unemployment associated with lack of company discourages or makes the older persons unable to take legal assistance. The senior citizens of Bangladesh do not have access to recreation or leisure time. Most of the recreation centers are occupied by the children and young people. Theculture of dedicated recreation center for the elders has not grown in Bangladesh. There is no or very little special facility in the transportation and traffic system for the old persons in Bangladesh. The constructions of the roads are not 
designed keeping the special needs of the aged persons in mind. The recent trend of small family culture has created another big problem in Bangladesh. The senior citizens are not getting adequate company from the family members or from other persons in the society. They are becoming isolated from the family as well as from the society which force them to face loneliness. The old parents are sometimes abandoned by the family members. Many times, the old parents become homeless. The elders are forced to stay in the old-age homes in wealthy families. Sometimes, the old members are forced to live separately from the family members. This new system of society makes the seniors very lonely, which results to unhappiness, hopelessness, physical and mental sickness, and finally unwanted and unpleasant early death.

\section{The Legal Framework Protecting the Older Section of the Society}

As the problems of old age are increasing day by day in every society, some steps have been taken both globally and at the national levels. Bangladesh has also come forward to adopt some legal framework. Some of the legal rules in the country are solid in nature in regards to the implementation aspect, and many are not specifically easy to implement. Thus, these laws and policies are shown below.

\subsection{International Initiatives for the Protection of the Rights of the Elderly People}

There are 703 million people aged 65 years or more in the world in 2019 and this number is projected to more than double reaching more than 1.5 billion within 2050 (UN, 2020). The $1^{\text {st }}$ of October is celebrated as the International Day of Older Persons as per the United Nations General Assembly Resolution in 1990 (Resolution 45/106, 1990). The first international initiative was the Vienna International Plan of Action on Ageing (1982), which places emphasis on the old age, health problem, inability to work, isolation from families, loneliness, etc. of the older people of the world. Thereafter, the United Nations adopted the Principles for the Older Persons in 1991 (Resolution 46/91, 1990). The Second World Assembly on Aging was held in 2002 with the participation of 159 countries adopting the Madrid International Plan of Action on Aging to respond to the challenges of current population ageing and to promote the development of a society for all ages. It focuses on three priority areas, such as, (a) older persons and development, (b) advancing health and well-being into old age, and (c) ensuring enabling and supportive environment (Art. 1, 2002). This conference tried to link the question of aging to other framework of social and economic development and human rights. The government can find it as a resource in enacting laws and policy.

\subsection{Constitutional Safeguards for the Elderly People in Bangladesh}

The Constitution has given an obligation to the government to introduce social security programs for the insolvent elderly people of the country. Article 15 (d) of the Constitution clearly declares that securing the 
right to social security and the provision of the basic necessities of life of the elderly people and other disadvantaged people is the fundamental duty of the state. This constitutional provision covers all the citizens in getting their basic needs such as food, clothing, shelter, education and medical treatment, and other rights. Irrespective of this provision, a particular focus is given to the aged persons. Although the above article is placed on the second part (Article. $15 \mathrm{~d}$ ) of the constitution which is not judicially enforceable, the state is morally bound to fulfill this obligation. So, the supreme law of the countryrecognizes the rights of the elderly people to enjoy some basic rights from the state. Under the constitutional obligations, the government has framed the National Policy for the Elderly 2006 for the safety and welfare of the elders. 'The Maintenance of Parents Act, 2013' is an important legislation for securing the basic necessities of the hopeless parents. Articles 17, 19, 20, 27, 28, and 29 of the constitution ensure the equal rights and opportunities of citizens includingthe older people. The state is responsible for removing illiteracy and to ensure free and compulsory education (Article. 17). It will ensure equal opportunities for all the citizens (Article 19). Employment opportunity for all citizens has been confirmed in Article 20 of the constitution. The constitution has declared the equality before the law and equal protection of the law for all the citizens (Article 27). No discrimination guaranty on the grounds of religion, race, caste, sex, and place of birth is confirmed by Article 28, while Article 29 ensures equality of opportunities in public employment. Likewise, other general rights and guaranties of the citizens enshrined in Articles 31-44 ensuring, especially, that the right to protection of law, life and personal liberty, against arbitrary arrest and detention, in respect of trial and punishment, freedom of movement, of assembly, of association, of speech, of occupation, of religion, property, etc. are also applicable for the senior citizens.

\subsection{National Policy on Elderly People}

Bangladesh has approved a national policy on older persons in 2013 for upholding the rights, socio-economic development, and total welfare of the elderly persons of the country in the line of Madrid International Plan of Action. The Ministry of Social Welfare is dedicated for implementing the welfare programs for the senior people. The goal of the policy is to ensure the respectful, poverty-free, active, healthy, and safe social life of the older persons. The government has declared older persons above 60 years to be senior citizens of the country as per the policy, and they accepted a plan of action to execute the policy mainly focusing on the health, transportation, and accommodation of the senior citizens. Some of the objectives set in the policy are: inclusion of aging issue in different national policies, facilitate the participation of older persons in local government, development process, enterprises and institutions, protection by making and implementing laws, priority of older person in health services, promotion of older person friendly housing and infrastructures, etc. To fulfill the goals and objectives, the policy includes, among others, the following principles as the obligations of the state: 
to recognize the old persons as the 'senior citizens' and introducing identity card for them, preserving seats in public transport and separate ticket counters, establishment of 'day care center' and 'old home', ensuring human rights, providing legal aids, ensuring enjoyment of property rights of elders, ensuring safety by law enforcing agencies, reduction of poverty, ensuring financial security through short and long term programs, introducing universal and noncontributory pension schemes, ensuring priority and special health care in government and private medical centers, introducing health service card and Geriatric Care and Medicine in the curricula of medical education, introducing education for the old persons, and implementing the policy through different committees under the Ministry of Social Welfare in association with private organizations and individuals. The priority and older-friendly construction of roads, public vehicles and the traffic system, recreations of the seniors, priority in utility services, extra benefits in saving schemes, and proper nutrition of the elderly people have been neglected in the policy which could make the elders' life more secured and comfortable.

\subsection{The Law for the Maintenance of Parents}

Parliament has enacted a new law 'The Maintenance of Parents Act, 2013' ensuring punishment for children who do not provide maintenance and proper care to their parents. As per provision of this law, the criminal court can compel the guilty son or daughter to take care of the parents by inflicting fine or imprisonment. This law may be used as a shield by the helpless parents as it provides proper remedy against society's new trend of separate living. A draft of 'Rules' has been framed titled 'The Maintenance of Parents Rules, 2017'under this law which is yet to be effective.

\subsubsection{A Wider Definition of Maintenance}

This law is not confined to include the traditional definition of maintenance, i.e., food, clothing, treatment and lodging, but rather it extends the meaning of maintenance to include company and care for the parents. Every adult son or daughter should regularly take care of the health condition of his/her father and mother and should arrange for their proper and necessary medical treatment. The term 'care' includes cleaning, toileting, feeding, medicining, medicating, exercising, etc. If the son cannot take care of his parents by himself for any practical and reasonable ground, he is expected to make arrangement for proper care by any family member or any caregiver (The Maintenance of Parents Rules, 2017 (draft), Rule 18). The son or daughter must take his/her parent to the doctor at least once a year and he/she should arrange for necessary diagnostic tests (The Maintenance of Parents Rules, 2017 (draft), Rule 17). A son living separately from his parents due to job or any other reasonable ground must give a reasonable amount of money to his parents (The Maintenance of Parents Act, 2013, Sec. 3). The law states that every son must live with his parents in the same residence and he cannot compel his parents to live in an 'old age home' or in a separate place (The Maintenance of Parents Act, 2013, Sec. 3). The parent's place of living should 
be clean with proper ventilation for air and light (The Maintenance of Parents Rules, 2017 (draft), Rule 16). In case of separate living for some practical reasons, for example, for job, business and education purpose, the son must allow his parents to live with him in the same place and when a son reasonably lives away from the parents, he must meet with his parents regularly (The Maintenance of Parents Act, 2013, Sec.3). Here, the term 'regularly' should be explained taking into consideration the distance of the child's place from his parents' residence, physical-mental-financial condition of parents, ability of child, child's sex, etc. Also, the daughter may be relaxed to perform this duty because according to the existing culture, a married daughter generally is dependent on her husband for her subsistence and movement in most families in Bangladesh (Mamun, 2017). The children must spend regular time and company with their parents. In the case of living away from the parents for a reasonable cause, the children must meet at least twice a year and must continue their communication and staying in touch with the parents using modern technology (The Maintenance of Parents Rules, 2017 (draft), Rule 19). The children will arrange adequate recreation including television, computer, newspaper, books, club, library, park, etc. as per the desires of the parents and according to the ability of the children (The Maintenance of Parents Rules, 2017 (draft), Rule 20).

\subsubsection{Punishment to Ensure Maintenance}

The aggrieved parent can file a complaint register criminal case to a judicial magistrate to establish his/her rights under this law (The Maintenance of Parents Act, 2013, Sec. 7). If the son does not provide maintenance or does not take care of his parent(s), he will be punished with fine which may extend to one lac taka. Thus, the non-payment may cause the son to be punished by imprisonment which may extend to three (3) months (The Maintenance of Parents Act, 2013, Sec. 5). The wife or any other relative, who instigates for non-maintaining the parents, will also be liable for the same punishment (The Maintenance of Parents Act, 2013, Sec. 5). This punishment may act as an effective tool to compel the ungrateful son to provide proper maintenance for his parents. However, this limited fine seems to be inadequate for the rich and wealthy sons or daughters who mainly do not take proper care of or give adequate time and company to their old parents. The law would be more fruitful and effective if it gives power to determine the amount of maintenance as an alternative to the family court (Mamun, 2017).

\subsubsection{Rules of Conduct for the Children}

A 'rules of conduct' has been prepared in the draft rules framed by the government to regulate the behaviors of the children towards their parents (The Maintenance of Parents Rules, 2017 (draft), Rule 13). This 'rules' will be finally made under the power given in section 9 of the Maintenance of Parents Act, 2013. There are twelve point rules of conduct set for the sons and daughters. Therefore, these include: (a) respectful behavior towards parents, (b) priority of the opinions of the parents, (c) arranging treatment and proper 
medication, (d) maintaining property and other rights of the parents, (e) ensuring opportunity of utilizing the experience and ability of the parents, (f) no misuse of the properties of the parents, (g) no misappropriation of other heirs' rights in the inheritance of the parents, (h) no blame to parents for havingno property, (i) trying to maintain the goodwill, status and family traditions of the parents, (j) managing financial saving scheme for the parents, $(\mathrm{k})$ ensuring the presence of the parents in family and social programs, (1) ensuring enjoyment of other civil and political rights of the parents. Subsequently, there will be monitoring committees to regulate the maintenance matters of the parents under the law in the national, district, upajela, city, municipal, and union levels (The Maintenance of Parents Rules, 2017 (draft), Rule 3-9).

\subsubsection{Parents' Care Center}

The draft 'rules' requires the government to establish necessary Parents' Care Centers for ensuring maintenance of the old parents who do notget proper care and maintenance from the family members (The Maintenance of Parents Rules, 2017 (draft), Chapter 5). The government can declare any institution to act as the Parents' Care Center. The center will have two corners, namely: 'Day Care Center' and 'Night Shelter'. The children who cannot take proper care of them during the day time due to their professional business cankeep their parents in the 'Day Care Center', while the children who cannot take adequate care of their parents at night, due to their professional businessor for special illness of the parents or for any other reasons, can ensure the proper care of their parents by keeping them in the 'Night Shelter'. The care in this center is regarded to be the last resort for the children to take care of their parents. However, this kind of center may be established privately also with permission from the government. The center will provide adequate and proper maintenance of the old parents, such as food, living components, treatment, safety and security measures, healthy environment and other necessaries things. The center will be financed by the government and throughprivate donations.

\subsection{The Personal Laws and Family Courts for the Maintenance}

There are family courts in every district of Bangladesh which have power, among others, to determine the maintenance of the parents according to the personal laws of the citizens. The parent can file a law suit under section5(d) of the Family Court Ordinance (1985) for maintenance. In this case, 'Jamila Khatun v. Roostom Ali' reported in 48 DLR (AD) 110. In addition, the highest court of Bangladesh opined that as per the provisions of the Muslim Law, the poor parents can file a suit for maintenance against the opulent children under the Ordinance of 1985. These courts have the jurisdiction to settle the matter amicably using the process of 'reconciliation' or 'compromise' given as judgment by the court on the maintenance after hearingfrom both the parties (Family Courts Ordinance, 1985, Sec. 10\&13).

\subsection{Free Legal support to the Older Persons}

Most of the older people of the country do not have adequate financial 
control to get legal assistance from the courts and the lawyers, and also to establish their necessary legal rights. Sometimes, they need to take legal actions against the family members for establishing the property rights and personal rights. In those situations, they become helpless and hopeless for want of money and other equipment. The legal Aid Act (2000) and the Legal Aid Rules (2014) provide free legal support to the poor old persons. The older persons who receive old-age allowance from the government and any insolvent or unemployed old persons can be provided legal aid from the government (Legal Aid Rules, 2014, Rule 2(2)(g), (m), (o) \& Rule 2(1) (a), (b)). The legal aid covers court fees, lawyers' remunerations, and other relevant fees to the litigation (Legal Aid Act, 2000, Sec. 2). This enactment covers all the insolvent senior citizens providing the free legal help as per theobligations mentioned in Article 15(d) of the constitution and in the national policy on the elderly people adopted in 2013.

\subsection{Aging Issue in other Soft Instruments of Bangladesh}

The issues of the elderly people have been directly or indirectly included in different policy of Bangladesh. The National Health Policy (2011)provides the basic health care to every citizen of the country including the older persons. It gives special focus on the health problems of the older section of the population (National Health Policy, 2011, Principle 3). One of the plansof action of the government is that it will provide special health care programs for the older people (National Health Policy, 2011, Plan of Action 31). The National Social Welfare Policy (2005) has been adopted with an objective to prevent the problems, empowerment, and development of the older people among others (National Social Welfare Policy, 2005, Preamble 1.3). A working strategy set in the policy for ensuring the social security of the elderlypeople is to provide financial assistance to the older persons of the country (National Social Welfare Policy, 2005, Principle 6.1.1). The policy reiterates to provide medical facilities, shelter, training, and rehabilitation to the poor older persons (National Social Welfare Policy, 2005, Principle 6.2.1). One of the chapters in the National Education Policy (2010) has been dedicated to theadult and non-formal education (National Education Policy, 2010, Chapter 3). The policy has provided objects and strategies of adult education with a goal to make all the adult persons literate. The aim of adult education is to create in the older persons a minimum level of understanding about health education, environment, accounts, human virtues, and professional skills. The government aims to include the private institutions, civil society, educated students, local educated persons and radiotelevision in the adult education movement to eradicate illiteracy from the country. Consequently, there is a National Population Policy (2012) which obliges the government to undertake special priority programs for the elderly people of the country with regard to health, education, and social security (National Population Policy, 2010, para.5.10).

\section{Old-age Allowance in Bangladesh}

Bangladesh is implementing programs to provide old age allowance since 1998 for the welfare and socio-economic protection of the old people (National Policy of Older Persons, 2013). The government is providing this financial benefit to the older persons of the country from the obligations enshrinedg in the 
Constitution, the National Policy on Older Persons (2013), and the National Social Welfare Policy (2005). The Department of Social Services is assigned to manage the old-age allowance program. Initially, 120 million taka was distributed among 0.40 beneficiaries at 100 taka per month in the 1997-1998 fiscal years. After then, the allocation increased to 18900 million taka among 3.1 million older persons in the year 2016-2017 at the rateof 500 taka per month. The male at the age of 65 and the female at 62 will be eligible to get the allowance (Implementation Manual for Old Age Allowance,2013, p.2). The government has allocated Tk. 2640 crore (2.64 billion) taka for 4.4 million (44 lakhs) people with the same rate in this regard in the fiscalyear of 2018-2019. A number of 4.9 million (49 lakhs) of older persons will receive the old-age allowance at the rate of 500 taka per month in the fiscal year 2020-2021, and the government has recently taken initiatives to send the old-age allowances through mobile banking system. This digitalization will surely minimize the difficulty, harassment, and corruption of the project. The government has allotted 2940 crores (2.940 billion) taka in the fiscal year 2020-2021 to cover the said 4.9 million (49 lakhs) older persons. The introduction of old-age allowance is a very good initiative in response to the social security of the senior citizens of the country, but the coverage of the number of older person is very little in comparison to the number of existing insolvent older people of the country. Besides, the monthly amount of allowance is as laughably low as a drop to an ocean. An old person can meet very little of his basic necessities with five hundred taka only.

\section{Social Safety Laws in Different Countries for Older Persons}

Our neighboring country, India, has enacted the Maintenance and Welfare of Parents and Senior Citizens Act (2007) which creates obligations on children and heirs to provide maintenance to parents and senior citizens. Thus, the failure to do so will make the person liable to suffer criminal penalty from court by a speedy, simple, and inexpensive mechanism. The stategovernments are obliged to establish old-age home in every district. Nepal has the Senior Citizens Act (2006) which requires each family member to maintain and care for the senior citizens according to the economic status and prestige of the member. Sri Lanka enacted the Protection of the Rights of Elders Act (2000) for the establishment of a National Council for Elders for the promotion and protection of the welfare and rights of the elders. The Elderly Rights Law(2013) of China requires the grown children to care and visit their aging parents frequently and ensure their financial and spiritual needs are met or to face fines or jail. Vietnam has the Law on the elderly (2009) and Taiwan enacted the Employment Services Act (2007) and Human Rights Act (1993) for the protection of the rights of the elderly people. The developed countries also ensure the rights and welfare of the older people through different laws,regulations, and programs.

\section{Conclusion}

We have adequate policies for the protection of the rights and social security of the older people in Bangladesh. As per its nature, these cannot be claimed as rights until the law is enacted in support of it. The constitutional provisions have also been placed in the second part of it which cannot be executed by $y_{0}$ courts 
according to the constitutional provisions. The governmentshould be more sensitized and active to fully implement the national policy on the older persons and other related policies. The maintenance law should be made more popular amidst the older people, and the judges and the social leaders should be sensitized by the government and non-government organizations working on this issue about the rights of the senior citizens. Steps should be taken to enact more laws to bring the letters into actions. Thesenior citizens are the architects of the civilization. It is our obligation to recognize their contributions towards the society. The society should beresponsible for looking after the welfare and security of the older section of the population. They should not be treated as a burden to the society. As per the culture of the Asian nature, generally the elders dedicate their lives and all properties for their next generation. So, they deserve proper respect and care from the family members, the society, and the state. The old-age allowance should cover almost all the senior citizens of the country and the amount of monthly allowance should reasonably be increased to meet the basic needs of a person. The construction of roads and the traffic system should be made friendly to the old people. The human rights organizations should create awareness in the society and among the older people about the rights and protections of the elderly persons. 


\section{References}

1.Barry Patricia (2020). "Medicare Eligibility Requirements-How to Qualify for Medicare." AARP Everw...AARP mentioned in

en.wikipedia.org/wiki/Old...age. Constitution of the People's Republic of

Bangladesh. Family Courts Ordinance (1985).

2.Hossain Mohammad Didar (2018). Constitutional, "Legal and Policy Frameworkof Human Rights for Older Persons in Bangladesh", 3 rd Annual Conference "Narrating Human Rights: Issues of Migration, Discrimination, and Protection of Human Rights in Southeast Asia", University of Jember, East Java, Indonesia.Implementation Manual for Old Age Allowance Program Revised (2013).

3.Mamun, MD. \& Abdullah, AL. (2017). "The Maintenance of Parents Act: A Protection Mechanism for Elderly People", in New Dimension of Law: Analysis of Selected Laws of Bangladesh. Edited by Abdullah Al Faruque \& M. Jasim Ali Chowdhury, published by HEQEP, CP-3156, May, pg. 67, Faculty of Law, University of Chittagong. 4.National Education Policy (2010).

5.National Health Policy (2011). 6.National Population Policy (2012).

7.National Policy of Older Persons (2013).

8.National Social Welfare Policy (2005).

9.Political Declaration and Madrid International Plan of Action on Aging (2002). 10.Siddqui, M.S. (2013). "Legal and Social Protection of Senior Citizens". The Financial Express, 25 January, pg. 13.

11.The Legal Aid Act (2000).

12.The Legal Aid Rules (2014).

13.The Maintenance of Parents Act (2013).

14.The Maintenance of Parents Rules (2017) (Draft).UN General Assembly Resolution 45/106.

15.UN General Assembly Resolution 46/91.

www.bd.undp.org/content/bangladesh/en/home/presscenter/pressreleases/2018/10 /18/society_responsible_for_senior_citizens.html, last visited on 21 August 2020. www.bd.undp.org/content/bangladesh/en/home/presscenter/pressreleases/2018/10 /18/society_responsible_for_senior_citizens.html. last visited on 21 August 2020. 16.www.un.org/en/events/olderpersonsday/. last visited on 16 August 2020. www.un.org/development/desa/ageing/international-day-of-older-personshomepage.html.last visited on 17 August $2020^{1}$ Resolution 45/106. www.unescap.org/sites/default/files/2.\%20MIPAA\%20Focal\%20Point\%20Prese ntation $1 \% 20$ (Bangladesh).pdf. last visited on 22 August 2020. www.unescap.org/sites/default/files/2.\%20MIPAA\%20Focal\%20Point\%20Prese ntation1\%20(Bangladesh).pdf. last visited on 22 August 2020. 17.www.dss.gov.bd/site/page/7314930b-3f4b-4f90-9605-886c36ff423a, last visited on 1 September 2020.

18.www.dss.gov.bd/site/page/7314930b-3f4b-4f90-9605-886c36ff423a, last visitedon 1 September 2020. 
